\title{
ARTE, POLÍTICA E EDUCAÇÃO AMBIENTAL: A CONTRIBUIÇÃO DO PENSAMENTO DE THEODOR ADORNO*
}

\author{
ART, POLITICS AND ENVIRONMENTAL EDUCATION: THE \\ CONTRIBUTION OF THE THEODOR ADORNO'S THINKING
}

\section{ARTE, POLÍTICA Y EDUCACIÓN AMBIENTAL: LA CONTRIBUCIÓN DEL PENSAMIENTO DE THEODOR ADORNO}

\author{
Heluane Aparecida Lemos De Souza ${ }^{\mathrm{I}}$ \\ Rosa Maria Feiteiro CaValari ${ }^{\text {II }}$ \\ ${ }^{I}$ Universidade Estadual Paulista \\ "Júlio de Mesquita Filho" (UNESP), Rio Claro/SP - Brasil

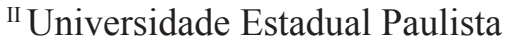 \\ "Júlio de Mesquita Filho" (UNESP), Rio Claro/SP - Brasil
}

Resumo A relação sociedade-natureza decorre, principalmente, da concepção de natureza que construímos ou, como afirma Bornheim (1985, p. 18), do "modo como o homem torna a natureza presente". A partir de Descartes (1596-1650) e Bacon (1561-1626), o conhecimento científico passou a ter uma função intervencionista, tornando-se necessário conhecer a natureza para dominá-la. A tal perspectiva de conhecimento, a "Teoria Crítica" elaborada pela Escola de Frankfurt se opõe radicalmente. Do mesmo modo, afirmamos que a atual crise socioambiental não pode ser resolvida apenas por meio da ciência e da tecnologia, embora não possamos abrir mão de sua contribuição, mas se torna, fundamentalmente, uma questão política (BORNHEIM, 1985). Nesse sentido, compreendemos a Educação e a Arte, em uma perspectiva política, essenciais para a transformação da realidade. A presente pesquisa, de abordagem qualitativa e natureza bibliográfica, tem como objetivo analisar a arte, na perspectiva de Theodor Adorno, bem como, identificar possíveis contribuições para a Educação Ambiental. Compreendemos que, para Adorno, a arte é uma forma de conhecimento, que possibilita uma experiência estética, e uma práxis política. Enquanto forma de conhecimento, a arte é, dialeticamente, "mimese" e "racionalidade". Da mesma maneira,

* Este trabalho é resultado de tese de doutorado. 
é condição para o estabelecimento da "experiência estética da natureza", que permite que esta seja compreendida como fenômeno e experienciada através da imagem. Por fim, a arte se relaciona com a sociedade não apenas pela sua produção e origem de seu conteúdo, mas, enquanto arte autônoma, ocupa posição antagônica à sociedade. A arte, segundo a concepção de Adorno, pode se aproximar da proposta de Carvalho $(1989,2006)$ para EA, de acordo com o nosso entendimento.

Palavras-chave: Theodor Adorno; Arte; Educação Ambiental.

ABSTRACT The relationship society-nature derives mainly from the conception of nature that we construct or, as Bornheim (1985, p. 18) asserts, "how man makes nature present" Since Descartes (1596-1650) and Bacon (1561-1626), the scientific knowledge started to have an interventionist function, being necessary the knowledge of nature to dominate it. The "Critical Theory" elaborated by the Frankfurt School radically opposes to this perspective of knowledge. Similarly, we affirm that the current socio-environmental crisis cannot be solved only through by science and technology, although we cannot give up their contribution, being fundamentally a political concern (BORNHEIM, 1985). Therefore, we understand Education and Art, from a political perspective, essential for the transformation of reality. The objective of this research, that has a qualitative approach and a bibliographical nature, is to analyze the art, from Theodor Adorno's perspective, as well as to identify possible contributions to Environmental Education. We understand that, for Adorno, art is a form of knowledge, that allows an aesthetic experience, and a political praxis. As a form of knowledge, art is, dialectically, "mimesis" and "rationality". Furthermore, art is a condition for establishing with the "aesthetic experience of nature", which allows it to be understood as a phenomenon and experienced through the image. Finally, art relates to society not only by its production and origin of its content but, as an autonomous art, occupying a position antagonistic to the society. The art, according to Adorno's conception, can approach Carvalho's proposal $(1989,2006)$ for EE, according to our understanding.

Keywords: Theodor Adorno; Art; Environmental Education.

RESUMEN La relación sociedad-naturaleza se deriva, principalmente, de la concepción de la naturaleza que hemos construido o, como afirma Bornheim (1985, p. 18), de la "manera en que el hombre hace la naturaleza presente" Desde Descartes (1596-1650) y Bacon (15611626), el conocimiento científico comenzó a tener una función intervencionista, haciendo necesario conocer la naturaleza para dominarla. A esta perspectiva de conocimiento, la "Teoría Crítica" elaborada por la Escuela de Frankfurt se opone radicalmente. Del mismo modo, afirmamos que la actual crisis socioambiental no puede ser resuelta solo por la ciencia y la tecnología, aunque no podemos renunciar a su contribución, pero es fundamentalmente una cuestión política (BORNHEIM, 1985). En este sentido, entendemos la educación y el arte, en una perspectiva política, fundamental para la transformación de la realidad. La presente investigación, de enfoque cualitativo y de carácter bibliográfico, tiene como objetivo analizar el arte, en la perspectiva de Theodor Adorno, así como identificar posibles contribuciones a la educación ambiental. Entendemos que, para Adorno, el arte es una forma de conocimiento, que permite una experiencia estética, y una praxis política. El arte es, 
dialécticamente, "mimesis" y "racionalidad"; es una condición para el establecimiento de la "experiencia estética de la naturaliza", que permite que se entienda la naturaleza como fenómeno; se relaciona con la sociedad no sólo por su producción y origen de su contenido, sino como un arte autónomo, que ocupa una posición antagonista de la sociedad. El arte, según la concepción de Adorno, puede acercarse a la propuesta de Carvalho $(1989,2006)$ para EA, según nuestra comprensión.

Palavras clave: Theodor Adorno; Arte; Educación Ambiental.

\section{INTRODUÇ̃̃o}

A relação sociedade-natureza ou, mais precisamente, as concepções de natureza e as relações que estabelecemos com a natureza humana e não humana são fundamentais para refletirmos acerca do que alguns autores têm denominado como "crise ambiental". Ou, como afirma Gerd Bornheim (1985, p. 18), "a questão toda se concentra, portanto, no modo como a natureza se faz presente para o homem; ou melhor: no modo como o homem torna a natureza presente.

A crise socioambiental que vivemos na atualidade, o aumento exponencial da destruição da natureza não humana, além da dominação do homem pelo próprio homem, marginalizando grupos e os colocando sob condição de miséria, distantes de alcançar a felicidade humana, coloca como imperativo ético e político a necessidade de reflexão e ação, ou da práxis, segundo alguns autores.

Considerando que fomos trazidos ao atual estado de coisas, entre outros fatores, pela forma predominante de nossa sociedade ocidental pensar e compreender o mundo, a saber, a partir da "razão instrumental", signo da Ciência moderna, é exigido que em nossa práxis busquemos alternativas outras de "tornar a natureza presente" (BORNHEIM, 1985) para, então, construirmos outra relação com a natureza, ou seja, uma relação de não dominação.

Parafraseando Bornheim (1985), historicamente a natureza está presentificada na sociedade ocidental por meio de uma relação de dicotomia entre sociedade e natureza. Essa relação decorre, entre outros fatores, de uma visão de natureza que opõe cultura e natureza, resultante, principalmente, da chamada ciência moderna. A ciência moderna deixa de ser especulativa, teorética, para se tornar pragmática e utilitarista; deixa de ser contemplação para ser intervenção (CAVALARI; CAMPOS; CARVALHO, 2001). Essa afirmação pode ser representada por meio de dois excertos de algumas das principais obras, uma de um filósofo racionalista e, outro, empirista, ambos pilares da ciência moderna: René Descartes (1596-1650) e Francis Bacon (1561-1626).

É emblemática a afirmação de René Descartes na "Sexta Parte" do Discurso do Méto$d o$, no qual ao se referir às noções da Física, distintas dos princípios considerados até então, permitiriam um conhecimento útil, aplicável às necessidades humanas, possibilitando que os homens se tornassem "senhores e possuidores da natureza": 
ações do fogo, da água, do ar, dos astros, dos céus e de todos os outros corpos que nos cercam, tão distintamente como conhecemos os diversos misteres de nossos artífices, poderíamos empregá-los da mesma maneira em todos os usos para os quais são próprios, e assim nos tornar como que senhores e possuidores da natureza. O que é de desejar, não só para a invenção de uma infinidade de artifícios, que permitiriam gozar, sem qualquer custo, os frutos da terra e todas as comodidades que nela se acham, mas principalmente também para a conservação da saúde [...] (DESCARTES, 1983, p. 63).

Na perspectiva de Francis Bacon, em sua obra Novum Organum ou verdadeiras indicações acerca da interpretação da natureza, o conhecimento, ou mais especificamente a ciência, possibilitada pelo novo método que propõe, mantém estreita relação com o poder. Para o exercício da dominação da natureza é necessário ao humano conhecê-la. Parece-nos evidente, como já citado, o caráter intervencionista atribuído ao conhecimento, bem como o abandono da necessidade de especular as causas dos fenômenos para se preocupar com a formulação de leis, "regras", a partir de sua observação:

Ciência e poder do homem coincidem, uma vez que, sendo a causa ignorada, frustra-se o efeito. Pois a natureza não se vence, se não quando se lhe obedece. E o que à contemplação apresenta-se como causa é regra na prática (BACON, 1979, p. 13).

Essa perspectiva de conhecimento foi enfatizada pelo Positivismo de Auguste Comte (1798-1857), no século XIX, permanecendo hegemônica na ciência, na sociedade ocidental, e, a partir de sua crítica, foram formuladas as bases da Teoria Crítica da Escola de Frankfurt, da qual Theodor Adorno é um dos principais pensadores.

Em referência à relação entre saber e poder, afirmada por Francis Bacon, Hans Jonas (2006, p. 236) discute o que denominou de "dialética do poder sobre a natureza", em sua obra O princípio responsabilidade: Ensaio de uma ética para a civilização tecnológica. Dado o sucesso, e não o fracasso do projeto de Bacon, como assevera Giacoia (2004), o poder exercido sobre a natureza se apresenta, hoje, como ameaça ao humano e a toda a biosfera:

[...] A fórmula baconiana afirma que saber é poder. Mas é o próprio programa baconiano que, no ápice do triunfo, revela-se insuficiente, com a sua contradição intrínseca, ou seja, o descontrole sobre si mesmo, mostrando-se incapaz de proteger o homem de si mesmo, e a natureza, do homem. [...] Bacon não poderia imaginar um paradoxo desse tipo: o poder engendrado pelo saber conduziria efetivamente a algo como um "domínio" sobre a natureza (ou seja, à sua superutilização), mas ao mesmo tempo a uma completa subjugação a ele mesmo (JONAS, 2006, p. 236-237).

Diante do contexto exposto, partimos da crítica à racionalidade realizada pelos pensadores da Escola de Frankfurt. De acordo com Horkheimer e Adorno (1985), ocorre o que os autores designam de uma "dialética do esclarecimento", isto é, o conhecimento que, segundo a tradição kantiana, deveria possibilitar a maioridade humana, sua autonomia e liberdade, resultou na dominação não apenas da natureza não humana, mas do homem 
pelo próprio homem. É essa forma de racionalidade que os autores denominam "razão instrumental", que, predominantemente, "torna a natureza presente" em nossa sociedade ocidental, resultando na crise socioambiental que ameaça nosso planeta como um todo, mas, principalmente, alguns grupos marginalizados pelo sistema capitalista.

Na reflexão que aqui propomos, no entanto, buscamos alternativas para pensar a crise socioambiental que vivemos na atualidade, não apenas na Teoria Crítica da sociedade, e a necessidade da "autorreflexão crítica" (ADORNO, 1995) por ela proposta, mas também na "Teoria Estética", de Theodor Adorno, considerada, se não a superação, a continuação da primeira. Embora seja necessário questionarmos a ênfase dada pela autora à teoria estética como única forma de oposição ao status quo, segundo Freitag (2004), diante da "profunda desconfiança em relação ao próprio ato de pensar" (p. 83), para Theodor Adorno "a teoria estética assume assim a posição de herdeira da teoria crítica, propondo-se como única forma possível de opor-se, teórica e praticamente, ao presente instituído" (p. 84).

Considerando as contribuições que tal perspectiva poderia significar ao campo específico da Educação Ambiental, realizamos um levantamento inicial, a partir das teses e dissertações produzidas no campo da EA, no período de 1981 a 2016, e identificamos que as contribuições da arte, na perspectiva da Teoria Crítica da Escola de Frankfurt, têm sido pouco expressivas no campo.

Inferimos, então, que talvez estejamos diante de um "blank spot" ou um "ponto em branco", como proposto por Stevenson et al. (2013, p. 513). Os autores afirmam, em relação ao campo da pesquisa em EA, que os "blind spots" se referem às áreas nas quais se sabe o suficiente para elaborarmos alguns questionamentos, porém, ainda não as respostas. Já os "blank spots" são áreas que, pouco exploradas, não se sabe o suficiente nem ao menos para a formulação de perguntas.

Tendo esse dado como referência, na pesquisa desenvolvida buscou-se questionar: que contribuições a Arte, a partir da perspectiva de Theodor Adorno, pode trazer para a Educação Ambiental, tendo como objetivo analisar a perspectiva de Theodor Adorno sobre a arte, e possíveis contribuições para a Educação Ambiental.

A pesquisa proposta é de abordagem qualitativa, de natureza bibliográfica. A opção por esse tipo de pesquisa se justifica dada a natureza e as especificidades do objeto investigado. De acordo com Gil (2010, p. 48), "a pesquisa bibliográfica é desenvolvida a partir de material já elaborado, constituído principalmente de livros e artigos científicos".

Na discussão que aqui propomos, destacamos a afirmação de Bornheim (1985) que defende que qualquer tentativa de transformar o atual estado de coisas não pode ser mediada apenas pela ciência e pela tecnologia, mas se tornou uma questão eminentemente política.

Dessa forma, buscamos destacar a contribuição do pensamento de Theodor Adorno, no que diz respeito à arte, para a Educação Ambiental, considerada sua dimensão política em uma perspectiva crítica e transformadora da realidade. Do mesmo modo, retomamos a perspectiva de autores do campo da EA que consideram o processo educativo como uma das possibilidades de enfrentamento da atual crise socioambiental. Nesse sentido, entendemos que a arte, como proposta por Adorno, pode ser vinculada à proposta de Carvalho $(1989,2006)$ para EA. 


\title{
A teoria CRítica e A dimensão POLítica da EDUCAÇão e da EDUCAÇÃO AMBIENTAL
}

Bornheim (1985, p. 24) afirma que "a questão ecológica já não pode ser resolvida em termos de ciência e tecnologia", mas, sim, "a natureza tornou-se agora, antes de tudo, um tema visceralmente e necessariamente político". Neste artigo, ao nos referirmos, como Bornheim, à dimensão política, nos situamos no campo da coletividade, no qual relações de poder se estabelecem, sendo necessário que os sujeitos se posicionem escolhendo entre a transformação ou a manutenção do status quo.

Estabelecida essa premissa, entendemos que a Educação se configura como prática social fundamental para que os sujeitos compreendam essa coletividade, participando dela de forma autônoma e crítica. Para tanto, é necessário que a consideremos, também, a partir de sua dimensão política.

Mas, o que significa defender a dimensão política da Educação? O que significa se referir à dimensão política em uma perspectiva crítica, na Educação e na Educação Ambiental?

Compreendemos que significa defender a sua não neutralidade, admitindo que, conscientes ou não de nossa ação educativa, contribuímos para a manutenção ou transformação da sociedade. Importante destacar que é comum associarmos à dimensão política apenas perspectivas críticas em relação à sociedade. De modo que, vale ressaltar, as perspectivas conservadoras, consideradas a partir de um posicionamento político, são igualmente políticas.

Severino (2002, p. 84) afirma que a Educação é "prática simultaneamente técnica, ética e política, atravessada por uma intencionalidade teórica e fecundada por uma significação simbólica, conceitual e valorativa". No que se refere à formação política, o autor apresenta a educação como responsável pela sociabilidade dos sujeitos, assegurando os bens necessários para sua humanização. Isto torna a educação uma "prática compromissada", que se dá em uma "relação indivíduo-sociedade sendo esta marcada pelo poder" (SEVERINO, 2002, p. 88).

"Fundamentalmente política" (SEVERINO, 2002, p. 89), a prática educativa deve estar compromissada em possibilitar aos educandos a percepção das relações de poder existentes na sociedade, desvelar o viés ideológico do processo e, evitando a reprodução das condições existentes, contribuir para sua transformação:

\begin{abstract}
A educação precisa garantir aos educandos clara percepção das relações de poder na realidade histórica das sociedades. Sem tal compreensão, os sujeitos não entenderão o significado de seu existir. Daí que o trabalho educativo deve subsidiar os estudantes para desvendar os vieses ideológicos do processo. Mediante a crítica aos sentidos falseados, a educação pode contribuir para a formação de nova consciência social nos educandos. Só assim a educação evitará a reprodução social e atuará como força de transformação, contribuindo para extirpar os focos de alienação (SEVERINO, 2002, p. 89).
\end{abstract}

É nessa mesma perspectiva que Saviani $(1985$, p. 94) discute a dimensão política da Educação, afirmando que "toda prática educativa, enquanto tal, possui uma dimensão política assim como toda prática política possui, em si mesma uma dimensão educativa". Em seus postulados, Saviani explica que a dimensão política da educação está no fortalecimento ou 
enfraquecimento dos sujeitos ou grupos para sua prática política na relação com seus antagônicos. Isto envolve, de forma central, a questão da apropriação dos instrumentos culturais:

\begin{abstract}
A dimensão política da educação consiste em que, dirigindo-se aos não-antagônicos a educação os fortalece (ou enfraquece) por referência aos antagônicos e desse modo potencializa (ou despotencializa) a sua prática política. [...] envolve, por sua vez, a apropriação dos instrumentos culturais que serão acionados na luta contra os antagônicos (SAVIANI, 1985, p. 94).
\end{abstract}

A partir de uma perspectiva histórica, Rodrigo (2001) identifica três vertentes no que se refere à relação entre educação, ética e política. Segundo a autora, a dimensão ético-política é substancial à educação, pois não é possível conceber um processo educativo que não envolva valores, comportamentos e a participação do sujeito na sociedade. Afirma, no entanto, que esses aspectos variam historicamente, dadas as diferentes concepções de homem, sua relação com a sociedade, e a ênfase em diversos aspectos que permeiam tais relações.

A Educação, embora não seja um tema central na produção da chamada Escola de Frankfurt, se faz presente em significativas contribuições, seja de forma esparsa, em escritos diversos, ou sendo objeto central de algumas obras. Os textos Educação após Auschwitz (1995) e Teoria da Semiformação (2010), de Theodor W. Adorno, são dois exemplos fundamentais para o campo da Educação, principalmente se considerarmos a urgência de recuperarmos a discussão referente à sua dimensão política em nossa contemporaneidade.

No ensaio Educação após Auschwitz, Adorno (1995, p. 119) afirma que "a exigência que Auschwitz não se repita é a primeira de todas para a educação". Com essa exigência, que nos emudece diante da força de sua dimensão ética e política, recoloca a vida humana e sua dignidade no centro do debate educacional.

Em Teoria da Semiformação aponta que, em nossa sociedade, ocorre uma "semiformação". Isso não significa, como afirmam alguns autores, uma formação incompleta, inacabada, mas sim uma "antiformação", resultante da "indústria cultural", esta que, segundo Horkheimer e Adorno (1985, p. 113) seria "o esclarecimento como mistificação das massas".

A "semiformação", segundo Adorno (2010, p. 39), nos coloca novamente sob ameaça da barbárie sendo que "a única possibilidade de sobrevivência que resta à cultura é a autorreflexão crítica sobre a semiformação, em que necessariamente se converteu".

A Educação Ambiental, fundamentalmente Educação, também reflete em suas práticas e teorias diferentes concepções não apenas de homem, sociedade e educação, mas das relações estabelecidas entre os humanos e entre estes e a natureza não humana. É impossível afirmarmos a existência de uma única "Educação Ambiental", e nossas escolhas, conscientes ou não, orientarão nosso fazer educativo na direção da manutenção ou transformação dessas relações. Dessa forma, é de fundamental importância que tais reflexões estejam integradas ao campo da Educação Ambiental.

Entre as diferentes posições relativas à perspectiva crítica da Educação Ambiental, destacamos a proposta de Carvalho $(1989,2006)$, já citada, na qual projetos de ação e investigações em EA devem contemplar, necessariamente, as dimensões dos conhecimentos, dos valores (éticos e estéticos) e de participação política, sendo a última, central. Tratam-se de dimensões da práxis humana e que devem ocorrer em caráter de reciprocidade: 
Nesta proposta, sempre considerando a dimensão política como central na caracterização do processo educativo em geral e para os processos de educação ambiental em particular, identifico duas outras dimensões - a de conhecimentos e a de valores (éticos e estéticos) - como constituintes de nossa práxis. Vistas como dimensões de complementaridade e de reciprocidade com a dimensão política, esses diferentes aspectos do nosso trabalho sustentam a possibilidade de intencionalizarmos as nossas ações, visando à formação de seres humanos (CARVALHO, 2006, p. 27).

Destacamos, da proposta de Carvalho (2006), especialmente a questão da Arte, associada mais diretamente, dada sua natureza, à dimensão estética (de valores), mas sempre em reciprocidade às demais dimensões. Nos propomos, aqui, a buscar contribuir para a formulação teórica em questão, considerando que a dimensão política, central, também se concretiza por meio da arte.

\section{ARTE: TEORIA ESTÉTICA, EDUCAÇÃO E EDUCAÇÃo AMBIENTAL}

Duarte (2012, p. 10), ao discutir nossas percepções diante de elementos da natureza ou daqueles criados pelo humano, questiona se "é correto dizer que existe uma categoria de objetos essencialmente sensoriais que seja totalmente particular e que tenha peculiaridades de várias ordens (na sua produção, no tipo de veiculação, no modo de sua recepção por nossa parte, na natureza de suas mensagens etc.)?" A essa categoria de objetos, de forma sucinta, definimos o que é a arte.

Discussões a respeito da arte podem ser realizadas por diferentes perspectivas. Aqui, privilegiamos as discussões realizadas pelo campo da Estética, parte da Filosofia que se ocupa, historicamente, entre outras questões, da arte.

Ainda segundo Duarte (2012), é interessante afirmar que a arte se vincula ao nosso sentimento de admiração diante da natureza não humana. Para o autor, do nosso sentimento de medo diante de uma natureza "não dominada" surgiu a ciência; do sentimento de admiração diante dela, surgiu a arte.

Parece correto dizer que do medo humano diante da Natureza resultaram os artifícios para dominá-la, que se manifestaram, mais recentemente, na ciência e na tecnologia. Da admiração pela Natureza adveio a sensibilidade voltada para a harmonia de todos os estímulos sensoriais (cores, sons, formas etc.). Todo nosso senso de beleza (tanto diante das coisas naturais como das criadas pelo homem) adveio, provavelmente, desse sentimento de admiração (DUARTE, 2012, p. 11-12).

Isso nos faz questionar, portanto, se a arte não nos possibilitaria outra relação com a natureza, diferente da relação estabelecida a partir da ciência moderna.

Às discussões que aqui empreendemos, importa-nos, ainda, enfatizar as relações entre arte e política. Segundo Napolitano (2011), essa relação é um tema muito estudado pelo campo das Ciências Humanas. Para o autor, de forma sintética, a relação entre arte e política pode ser caracterizada de duas maneiras, a saber: uma arte que é a expressão de uma perspectiva política estabelecida e definida previamente; uma arte que se posiciona de modo crítico e contestatório a um contexto já estabelecido: 
[...] Grosso modo, a relação entre arte e política pode se apresentar sob dois aspectos básicos: como arte ligada e a serviço de uma ordem política vigente e de um poder constituído; ou como arte engajada que critica esse mesmo poder e uma dada ordem vigente, relacionando mais a processos de lutas de caráter contestatório (NAPOLITANO, 2011, p. 26).

Napolitano (2011, p. 26), conceitualmente, propõe que a "arte politizada" pode se caracterizar por "arte militante" ou "arte engajada". A "arte militante" é mobilizada por uma ideologia política delimitada, estando relacionada à ação de um grupo específico, enquanto na "arte engajada" há uma motivação mais ampla, que envolve questões valorativas, voltadas à coletividade; o contexto político, porém, não é o contexto do qual parte, mas, sim, ao qual acaba por se destinar.

Buscando a interface do campo da Arte com o campo da Educação, é importante enfatizar que, sendo ambas práticas sociais caracterizadas pela dimensão política, não há neutralidade, sendo que essa relação pode ocorrer por diferentes perspectivas, influenciadas pelo contexto social, político e econômico.

Salomé (2013), ao refletir sobre o papel da arte no contexto capitalista, afirma que são diversas as discussões a respeito da importância da arte na escola, cujos conhecimentos possibilitam a interação crítica e criativa com a realidade. A autora descreve que, muitas vezes, em reflexo a outras separações ocorridas na sociedade capitalista, a arte no contexto escolar é desvinculada do conhecimento, e considerada dentro de um "caráter funcional":

\begin{abstract}
A separação entre artista e sociedade, arte e trabalho, se reflete no interior da escola no discurso que separa a arte do conhecimento, desconsiderando a dimensão do trabalho artístico e assumindo o caráter funcional da arte provida de uma utilidade, seja para embelezar os murais da escola, para ilustrar as aulas das demais disciplinas do currículo, ou ainda para o descanso e o lazer dos alunos (SALOMÉ, 2013, p. 4).
\end{abstract}

Salomé (2013) explana que essas práticas eram comuns nas escolas brasileiras, principalmente nas décadas de 1960 e 1970, vinculando-se a arte à experimentação de materiais, cópias, ou desenvolvimento de habilidades manuais na confecção de artesanatos, passíveis de serem vendidos e, assim, atrelada à formação para o mercado de trabalho.

Ao contrário desse viés utilitarista, Salomé $(2013$, p. 1) defende que a arte na escola deve ser compreendida como criação simbólica, que relaciona o mundo vivido àquele pensado, delineando uma "ponte entre o sensível e o inteligível, entre o cognoscível e a experiência estética".

Em relação ao Ensino da Arte, Silva e Araújo (2007) buscaram compreender as tendências e concepções de ensino de arte especificamente no contexto educacional brasileiro. Os autores apresentam três diferentes tendências, nas quais a arte pode ser compreendida enquanto "técnica", "expressão e atividade" ou "conhecimento". Essas distintas tendências e concepções, enfatizam os autores, não se limitaram ao período histórico de seu surgimento e estão presentes, de forma antagônica, nas práticas dos educadores. 
[...] Na Tendência Pré-Modernista, encontraremos a concepção de Ensino da Arte como Técnica; já na Tendência Modernista, vamos encontrar a concepção de Ensino da Arte como Expressão e também como Atividade; e finalmente na Tendência Pós-Modernista, a concepção de ensino da Arte como Conhecimento (SILVA; ARAÚJO, 2007, p. 4).

E o campo da Educação Ambiental, enquanto Educação, também realiza interface com a arte? Em caso afirmativo, é importante questionarmos a partir de que perspectivas teóricas, e quais abordagens, funções ou papéis são atribuídos à expressão artística pela EA. Além disso, questionamos, neste artigo, se a aproximação entre a arte e o campo da Educação Ambiental é realizada a partir da perspectiva de Theodor Adorno ou de outros pensadores da Escola de Frankfurt.

Buscando elaborar um panorama da questão da arte na EA, analisamos os resumos de teses e dissertações constantes no Banco de Teses do Projeto EArte, ${ }^{1}$ o que nos possibilitou, além de compreender as discussões já realizadas no campo, considerar as contribuições que nossas reflexões poderiam significar para a Educação Ambiental.

De um total de 4.205 pesquisas produzidas no período de 1981 e 2016, 69 pesquisas em EA realizam de forma central, ou com certa ênfase, a interface com a arte. Nesses trabalhos, observamos numerosos e diferentes papéis atribuídos à arte em relação à Educação Ambiental, no entanto, destacamos a ênfase na arte enquanto um "meio", portanto, esvaziando-a de seu potencial político e crítico.

Quanto às perspectivas teóricas, poucos resumos explicitam essa vinculação. Com base no que foi analisado, a perspectiva da arte a partir da Teoria Crítica da Escola de Frankfurt ainda é pouco expressiva no campo, havendo referência à "teoria crítica" em duas pesquisas e à teoria de Walter Benjamin em uma delas, totalizando três referências.

\section{A arte na Perspectiva de Theodor Adorno: contribuições Para A EDUCAÇÃo AMBIENTAL}

Theodor Adorno é considerado um dos principais pensadores da chamada Escola de Frankfurt, grupo de pensadores que produziram algumas das reflexões mais importantes do século XX. O termo "Escola de Frankfurt" "refere-se, simultaneamente, a um grupo de intelectuais e a uma teoria social" (FREITAG, 2004, p. 9). Trata-se de "um grupo de intelectuais marxistas, não ortodoxos" (FREITAG, 2004, p. 10) e, ainda segundo Freitag (2004), embora o termo sugira certo consenso ou unidade do ponto de vista político e epistemológico dos diferentes intelectuais vinculados ao Instituto, esse consenso raramente existiu. Contudo, há elementos que permitem reuni-los sob a perspectiva da "teoria crítica":

[...] O que caracteriza a sua atuação conjunta é a sua capacidade intelectual e crítica, sua reflexão dialética, sua competência dialógica ou aquilo que Habermas viria a chamar de "discurso", ou seja, o questionamento radical dos pressupostos de cada posição e teorização adotada (FREITAG, 2004, p. 33-34).

' Projeto "Educação Ambiental no Brasil: análise da produção acadêmica (teses e dissertações)" - "Projeto EArte", projeto de caráter interinstitucional, que busca mapear a produção teórica (teses e dissertações) em Educação Ambiental no país. http://www.earte.net/ 
Dentro desse grupo, o pensamento de Adorno segue uma trajetória que é "o caminho da crítica da cultura à teoria estética que se concebe como interpretação do protesto contido nas manifestações artísticas" (FREITAG, 2004, p. 68).

Dessa forma, antes de realizarmos um aprofundamento acerca das reflexões específicas sobre a teoria estética de Adorno, é necessário discutirmos, mesmo que de maneira breve, o que ele denominou, com Horkheimer, de "dialética do esclarecimento". Para Horkheimer e Adorno (1985), o esclarecimento, que iria possibilitar a autonomia e liberdade do homem, ou a sua "maioridade" na expressão kantiana, associado ao sistema social, político e econômico capitalista e sob o signo da técnica, transformou-se em "razão instrumental", dissociado das finalidades humanas e possibilitando a dominação da natureza não humana e do homem pelo próprio homem.

No sentido mais amplo do progresso do pensamento, o esclarecimento tem perseguido sempre o objetivo de livrar os homens do medo e de investi-los na posição de senhores. Mas a terra totalmente esclarecida resplandece sob o signo de uma calamidade triunfal (HORKHEIMER; ADORNO, 1985, p. 19).

Diante, portanto, da instrumentalização da razão, Adorno aposta na teoria estética, e na arte, como possibilidade de reflexão crítica e transformação de nossa sociedade. De acordo com Freitag (2004, p. 81):

[...] Depois que a cultura se transformou gradativamente em indústria cultural, depois que a arte perdeu sua aura, dissolvida no consumo de massa, e depois que a filosofia e a ciência se reduziram ao positivismo, em que sua pobreza somente permite a reflexão afirmativa do existente, restam poucas alternativas à sociedade moderna de assegurar sua auto-reflexão e crítica. Uma delas seria a estética $[\ldots]$.

Ainda segundo Freitag (2004), a teoria estética enquanto "herdeira" da teoria crítica possibilita reconhecer na arte a negação ao atual estado de coisas, resistindo e lutando contra a sociedade estabelecida, a partir do ideal de felicidade e a transcendência utópica da sociedade. É necessário que ressaltemos, no entanto, nosso questionamento quanto à afirmação da autora no sentido de apresentar a teoria estética como "única" alternativa de resistência à sociedade e busca por esses ideais.

Para Freitag (2004, p. 84, grifos do autor):

A teoria estética assume assim a posição de herdeira da teoria crítica, propondo-se como única forma possível de opor-se, teórica e praticamente, ao presente instituído. Somente através da teoria estética seria possível, no parecer de Adorno, evitar a unidimensionalização e a dissolução da arte no cotidiano. A teoria estética consegue deduzir da arte os momentos críticos e a negatividade que ela representa, iluminando a obra de arte e compreendendo-a como representação do real em múltiplas dimensões contraditórias. Reconhece que a arte é o último reduto, a "reserva ecológica" da sociedade, em que a mensagem da "promessa de felicidade" permanece, contendo assim um conteúdo utópico que transcende a representação do real. Por isso mesmo a teoria estética passa a ser a única e úl- 
tima forma de resistência possível ao fechamento geral das estruturas materiais e societárias. Ao desenvolver a teoria estética Adorno está, pois, teorizando sobre a arte, mas ao mesmo tempo lutando com a arma de sua nova teoria contra o status quo alienador.

É a partir do exposto que dialogamos com a teoria estética de Adorno, buscando contribuições para a temática ambiental e, mais precisamente, para a Educação Ambiental, em uma perspectiva crítica de transformação da realidade. Iniciamos afirmando que a arte, sob a perspectiva de Adorno, pode ser considerada sob três perspectivas inter-relacionadas, a saber, como uma forma de conhecimento, como uma experiência estética e como uma práxis política.

Enquanto forma de conhecimento, a arte é, dialeticamente, "mimese" e "racionalidade":

[...] A sentimentalidade e a fragilidade de quase toda a tradição do pensamento estético devem-se a que ele silenciou a dialéctica de racionalidade e mimese, imanente à arte. Isso prolonga-se no espanto perante a obra de arte técnica como se ela tivesse caído do céu: as duas noções são intrinsecamente complementares (ADORNO, 2013a, p. 89).

Permanece na arte o comportamento mimético. Segundo Adorno (2013b, p. 140), o comportamento mimético é o comportamento central da vida primitiva que, por meio da "imitação imediata", associada às práticas mágicas, buscava a interferência humana nos fenômenos da natureza, visando exercer poder sobre ela. O comportamento mimético vai, no entanto, desaparecendo no processo do esclarecimento, mas permanece na arte como herança de sua relação com as práticas mágicas em sua origem.

A permanência do comportamento mimético na arte, segundo Adorno (2013b, p. 140), é como um "retorno da natureza pela arte", a manifestação de uma natureza injustiçada, reprimida, silenciada pela razão dominadora.

Para Adorno (2013b, p. 142), o comportamento mimético não significa, entretanto, uma cópia do objeto, mas um "impulso imitador", no qual a representação se transforma na "coisa em si". Aqui, podemos afirmar que existe na arte a relação do "idêntico" e do "não idêntico". Isso possibilita, segundo Adorno (2013b, p. 143), uma relação não de dominação entre sujeito e objeto, mas de "semelhança", "afinidade".

Adorno (2013b) afirma que, no entanto, a arte não pode ser reduzida ao mimético, ao arcaico, ao natural. Ela faz parte do processo que Weber denominou de "desencantamento do mundo", e participa do processo de dominação da natureza. Ocorre o que Duarte (1993, p. 133) denomina de um "domínio estético da natureza", que significa um "dispor consciente do artista sobre seu material" (p. 118). Essa denominação, segundo o autor, de forma ambígua, se aproxima da dominação capitalista da natureza e a critica.

A arte, como herança mágica, conserva o que pode ser denominado de "mana". E o que isto significa?

[...] No mundo luminoso da religião grega perdura a obscura indivisão do princípio religioso venerado sob o nome de "mana" nos mais antigos estágios que se conhecem da humanidade. Primário, indiferenciado, ele é tudo o que é 
desconhecido, estranho: aquilo que transcende o âmbito da experiência, aquilo que nas coisas é mais do que sua realidade já conhecida. O que o primitivo aí sente como algo de sobrenatural não é nenhuma substância espiritual oposta à substância material, mas o emaranhado da natureza em face do elemento individual. [...] O mana, o espírito que move, não é nenhuma projeção, mas o eco da real supremacia da natureza nas almas fracas dos selvagens. A separação do animado e do inanimado, a ocupação de lugares determinados por demônios e divindades, tem origem nesse pré-animismo. Nele já está virtualmente contida até mesmo a separação do sujeito e do objeto. Quando uma árvore é considerada não mais simplesmente como árvore, mas como testemunho de uma outra coisa, como sede do mana, a linguagem exprime contradição de que uma coisa seria ao mesmo tempo ela mesma e outra coisa diferente dela, idêntica e não idêntica (HORKHEIMER; ADORNO, 1985, p. 28-29).

A arte, portanto, é o idêntico e o não idêntico, questionando a dominação por meio do conceito na relação sujeito e objeto. É o mana que representa o "emaranhado da natureza" em nós, silenciado pelo esclarecimento sob o signo da razão dominadora. Está relacionado à aura, conceito desenvolvido por Walter Benjamin (2012), sendo inexistente nos produtos da chamada "indústria cultural".

Em relação à arte enquanto expressão estética, destacamos o conceito de "experiência estética da natureza" (ADORNO, 2013a, p. 106). Em uma articulação entre o belo artístico e o belo natural, refere-se à natureza unicamente como fenômeno, e não como matéria para o trabalho, para a ciência, e reprodução da vida, humana e não humana. $\mathrm{Na}$ "experiência estética da natureza" a natureza é experienciada como imagem, e não é objeto de ação (ADORNO, 2013a).

O modo de articulação do belo natural e do belo artístico revela-se na experiência que àquele se aplica. Ela refere-se à natureza unicamente enquanto fenômeno, não enquanto material de trabalho e reprodução da vida, muito menos ainda enquanto substrato da ciência. Tal como a experiência artística, a experiência estética da natureza é uma experiência de imagens. A natureza enquanto belo fenomenal não é percebida como objecto de acção (ADORNO, 2013a, p. 106).

O belo natural, no entanto, segundo Adorno (2013a), não se deixa reproduzir. A fidelidade da arte à natureza enquanto fenômeno está na "expressão da sua própria negatividade" (ADORNO, 2013a, p. 109), ou seja, na impossibilidade de reproduzi-la. Ao contrário do que possamos considerar, a arte naturalista distancia-se da natureza, tratando-a como matéria-prima, como faz a indústria (ADORNO, 2013a).

Segundo Adorno (2013a), é a partir do silêncio da obra de arte que a natureza se expressa. E, nesse sentido, é a filosofia, a teoria estética, que conseguirá dizer o que a arte não diz, mas só por ela pode ser dito sem dizê-lo:

[...] Para lá da aporia do belo natural, menciona-se aqui a aporia da estética no seu conjunto. O seu objecto define-se como indeterminável, negativamente. Por isso, a arte necessita da filosofia, que a interprete, para dizer o que ela não consegue dizer, enquanto que, porém, só pela arte pode ser dito, ao não dizê-lo (ADORNO, 2013a, p. 116). 
Por fim, apresentamos a arte como uma práxis política. Para Adorno, a arte é social não apenas pelo seu contexto de produção, seu vínculo com o já existente, mas principalmente, pela sua postura de oposição e negação frente ao estado de coisas:

[...] Mas a arte não é social apenas mediante o modo da sua produção, em que se concentra a dialéctica das forças produtivas e das relações de produção, nem pela origem social do seu conteúdo temático. Torna-se antes social através da posição antagonista que adota perante a sociedade e só ocupa tal posição enquanto arte autónoma (ADORNO, 2013a, p. 340).

Sua contribuição à sociedade se dá como resistência a esta, não sua imitação. Torna-se uma práxis social, já que "ao abster-se da práxis, a arte torna-se esquema de uma práxis social: toda a obra de arte autêntica opera uma revolução em si” (ADORNO, 2013a, p. 344).

[...] A arte só se mantém em vida através da sua força de resistência; se não se reifica, torna-se mercadoria. $\mathrm{O}$ seu contributo para a sociedade não é comunicação com ela, mas algo de muito mediatizado, uma resistência, em que a evolução social se reproduz em virtude do desenvolvimento intra-estético, sem ser a sua imitação (ADORNO, 2013a, p. 341).

Afirma que é através da forma, por meio da qual os conteúdos se expressam, que a dimensão política da arte se realiza, de modo periférico, influenciando o espírito que contribuirá, de maneira direta, para os processos de transformação da sociedade. Nesse sentido, aproxima-se de Herbert Marcuse, para quem "o potencial político da arte baseia-se apenas na sua própria dimensão estética” (MARCUSE, 2016, p. 11).

[...] Pode duvidar-se que as obras de arte se empenhem politicamente; quando isso acontece é quase sempre de modo periférico; se elas se esforçam por tal, costumam desaparecer sob o seu conceito. O seu verdadeiro efeito social é altamente indirecto, participação no espírito que contribui, por processos subterrâneos, para a transformação da sociedade e se concentra nas obras de arte; adquirem tal participação apenas pela objectivação (ADORNO, 2013a, p. 364).

Para Adorno (2013a), a libertação da forma demonstra a sociedade liberta. Por isso, no "mundo administrado" a emancipação da forma é impedida. Revolucionária, segundo ele, é a arte que nega a realidade, fomentando a participação política do que, por princípio, não pode ser considerado politicamente:

[...] Se, na arte, as características formais não podem ser interpretadas politicamente, nada, porém, existe nela de formal sem implicações conteudais, que se estendem até à política. Na libertação da forma, tal como a deseja toda a arte genuinamente nova, cifra-se antes de tudo a libertação da sociedade, pois, a forma, a coerência estética de todo o elemento particular, representa na obra de arte a relação social; eis por que o estado de coisas existente repele a forma emancipada (ADORNO, 2013a, p. 384). 
Segundo a própria "teoria crítica", apenas a consciência da sociedade não possibilita transpor a estrutura imposta. No entanto, a arte transcende o social na crítica que realiza (ADORNO, 2013a).

Por fim, para Adorno (2013a), é preferível que a arte desapareça do que, escondida por uma falsa positividade, deixe de ser a expressão do sofrimento. Como função política, a arte se mantém como memória do sofrimento humano, como forma de resistência à barbárie.

[...] valia mais desejar que um dia melhor a arte desapareça do que ela esquecer o sofrimento, que é a sua expressão e na qual a forma tem a sua substância. Esse sofrimento é o conteúdo humano, que a servidão falsifica em positividade. Se, conforme ao desejo, a arte futura se tornasse de novo positiva, a suspeita de uma persistência real da negatividade seria aguda; ela é-o constantemente, porque a regressão ameaça sem cessar, e a liberdade, que no entanto seria a liberdade a respeito do princípio de propriedade, não pode ser possuída. Mas que seria a arte enquanto historiografia, se ela se desembaraçasse da memória do sofrimento acumulado? (ADORNO, 2013a, p. 391-392).

Com base nas discussões aqui realizadas, parece-nos possível estabelecer um diálogo entre os aspectos da arte, a partir da perspectiva de Theodor Adorno e a proposta de Carvalho (2006), já apresentada, para a Educação Ambiental, buscando contribuir, de forma mais sistemática, para as discussões no campo da EA, considerando a arte um importante elemento na crítica e superação da concepção de natureza predominante em nossa sociedade e a relação de dominação da natureza, humana e não humana, dela decorrente. Ambas as propostas possuem a centralidade na dimensão política, em reciprocidade com aspectos da dimensão de conhecimentos e dimensão axiológica, posicionando-se em uma perspectiva política crítica e de transformação da realidade.

\section{CONSIDERAÇÕES FINAIS}

A arte, sob a perspectiva de Theodor Adorno, como proposta em sua "Teoria Estética", pode ser compreendida, fundamentalmente, em sua dimensão política. Compreendemos que, para Adorno, a arte é uma forma de conhecimento, uma práxis política, além de uma expressão estética que se vincula às duas outras dimensões.

Enquanto forma de conhecimento, a arte é apresentada por Adorno como um conhecimento que se diferencia da racionalidade do "mundo administrado" e que se expressa no esclarecimento enquanto "indústria cultural". Enquanto conhecimento que se relaciona e renuncia ao mundo, a arte critica essa forma de racionalidade. Ela é, dialeticamente, "mimese" e "racionalidade", na qual os elementos sensíveis participam do ato de conhecer. Por intermédio do conceito de "mana", que está associado às práticas mágicas, Adorno expressa a ideia de contradição no próprio "objeto", que não é passível de objetivação, no qual algo pode ser ele e outra coisa, seu "idêntico e não idêntico".

Para o frankfurtiano, a arte é, também, condição para outra experiência com a natureza. Considerando a arte enquanto "experiência estética da natureza", ela permite que a natureza seja compreendida como fenômeno, experienciada através da imagem. Essa 
compreensão difere da visão predominante de natureza que, segundo o autor, a considera enquanto base para o trabalho humano, para a ciência, e manutenção da vida. Trata-se, portanto, de uma natureza que não é objeto de intervenção e dominação humana. A partir dessa outra visão de natureza, possibilitada pela arte, podemos, então, construir uma nova relação com a natureza não humana e humana.

Por fim, a arte para Theodor Adorno mantém relação com a sociedade e, destacamos, apresenta uma dimensão fundamentalmente política.

Para Adorno, a arte se relaciona com a sociedade não apenas pela sua produção e pela origem de seu conteúdo, mas por, enquanto arte autônoma, ocupar uma posição antagônica à sociedade. Ela é, ambiguamente, arte autônoma e "fato social".

Segundo Adorno, as obras de arte autênticas são orientadas pelo conceito de sociedade em uma perspectiva crítica. Além disso, há uma estreita relação entre a forma da arte e a dimensão política, sendo que na libertação da forma está implícita a sociedade liberta.

Adorno considera, com base na teoria crítica, que apenas a consciência da sociedade não possibilita a transposição da sua estrutura, da qual, inclusive, a arte faz parte, mas que a arte transcende o social a partir de sua crítica. Para ele, a arte necessita manter-se enquanto memória do sofrimento vivido pelo humano, significando uma forma de resistência contra a barbárie.

Em nossa pesquisa analisamos que, no campo específico da Educação Ambiental, são diversas as abordagens, as funções ou os papéis atribuídos à arte em sua interface com a EA, nas quais destacamos, em forma de crítica, a predominância da arte instrumentalizada, ou seja, enquanto um recurso ou um meio para fins diversos, anulando seu potencial político, crítico e transformador.

Concluímos que, como é possível compreender, nossas contribuições não se concretizam em propostas de ações práticas, de apropriação da arte enquanto um "meio" nas propostas pedagógicas que envolvam a temática ambiental. As contribuições se fazem no plano teórico, buscando propor ao campo da EA novas perspectivas para o diálogo com a arte, compreendida, além de sua dimensão estética, também enquanto uma forma de conhecimento e uma práxis política. Nesse sentido, que possa contribuir para a crítica e transformação da sociedade em suas diversas relações, humanas e com a natureza não humana, além de seu compromisso ético, principalmente no que diz respeito à questão da dignidade do humano e do não humano.

Em nossas análises, ao buscarmos contribuir diretamente para o campo da EA, destacamos que a arte, como proposta por Adorno, nos possibilita aproximá-la da proposta de Carvalho (2006) para a Educação Ambiental, considerando-se a necessidade de contemplar, para as práticas e produções teóricas em EA, as dimensões política, de valores éticos e estéticos e de conhecimentos, com a centralidade da dimensão política.

É preciso enfatizar que, quando nos referimos à natureza, nossa preocupação não se apresenta apenas em relação à ameaça das espécies em seu conjunto, mas com a vida de cada indivíduo em sua existência e expressão, ameaçadas por um sistema no qual sua dignidade desaparece frente aos valores econômicos. Interessa-nos defender a dignidade da vida humana e não humana, e o ideal de felicidade de toda a humanidade.

Que, a exemplo do pensador frankfurtiano, defendamos a arte enquanto testemunho da "história a contrapelo", 2 expressando o lado dos vencidos, que fale pelas e a favor das vítimas, a favor dos vencidos, humanos e não humanos:

2 Expressão de Walter Benjamin, em "Sobre o conceito da história". 
[...] a grande arte, também no particular, volte a tomar partido, uma e outra vez, pelas vítimas; que a história esteja escovada à contrapelo; que, portanto, não seja a história do ponto de vista do vencedor - poderia talvez ser dito -, mas a escrita inconsciente da história que fazem as épocas, a escrita da história do ponto de vista da vítima; e que o que ressoe em verdade nas obras de arte seja sempre a voz da vítima e que não exista arte que não tenha, intrinsecamente, esta capacidade (ADORNO, 2013c, p. 159-160). ${ }^{3}$

Que a utopia, a possibilidade de dignidade e felicidade estejam, também, no nosso testemunho do sofrimento da natureza, em suas diversas expressões, para que politicamente nos posicionemos a favor da transformação. Que a voz que aqui se expressa, a exemplo do que defende Cavalari (2018), seja a voz dos oprimidos, voz expressa em linguagem humana ou nos diversos sons da natureza.

\section{REFERÊNCIAS}

ADORNO, Theodor. W. Teoria Estética. Lisboa: Edições 70, 2013a (Arte \& Comunicação).

ADORNO, Theodor. W. Clase 4. In: ADORNO, Theodor. W. Estética (1958-1959). Buenos Aires: Las cuarenta, 2013b, p. 121-144 (Colección Mitma).

ADORNO, Theodor. W. Clase 5. In: ADORNO, Theodor. W. Estética (1958-1959). Buenos Aires: Las cuarenta, 2013c, p. 145-171 (Colección Mitma).

ADORNO, Theodor. W. Teoria da Semiformação. In: PUCCI, Bruno; ZUIN, Antônio Álvaro Soares.; LASTÓRIA, Luiz A. Calmon Nabuco (Org.). Teoria Crítica e Inconformismo: novas perspectivas de pesquisa. Campinas: Autores Associados, 2010, p. 7-40.

ADORNO, Theodor. W. Educação após Auschwitz. In: ADORNO, Theodor. W. Educação e Emancipação. São Paulo: Paz e Terra, 1995, p. 119-138.

BACON, Francis. Novum Organum ou verdadeiras indicações acerca da interpretação da natureza. Tradução e notas de José Aluysio Reis de Andrade. São Paulo: Abril Cultural, 1979 (Os pensadores).

BENJAMIN, Walter. A obra de arte na era de sua reprodutibilidade técnica. In: BENJAMIN, Walter. Magia e técnica, arte e política: ensaios sobre literatura e história da cultura, 8. ed. Revista. São Paulo: Brasiliense, 2012, p. 179-212 (Obras escolhidas v. 1).

3 [...] el gran arte, también en lo particular, vuelva a tomar partido, una y outra vez, por las víctimas; que la historia esté peinada a contrapelo; que, por lo tanto, no se ala historia desde el punto de vista del vencedor podría quizá decirse -, sino la escritura inconsciente de la historia que hacen las épocas, la escriptura de la historia desde el punto de vista de la víctima; y que lo que resuene en verdad en las obras de arte sea siempre la voz de la víctima y que no exista arte que no tenga, intrínsecamente, esta capacidad (ADORNO, 2013c, p. 159-160). 
BORNHEIM, Gerd. Filosofia e Política Ecológica. Revista Filosófica Brasileira [S.1.], v. 1, n. 2, p. 16-24, 1985.

CARVALHO, Luiz Marcelo de. A temática ambiental e a escola de $\mathbf{1}^{\mathbf{0}}$. grau. São Paulo, 1989, 282s. Tese (Doutorado em Educação) - Faculdade de Educação, Universidade de São Paulo, São Paulo, 1989.

CARVALHO, Luiz Marcelo de. A temática ambiental e o processo educativo: dimensões e abordagens. In: CINQUETTI, Heloisa Chalmers Sisla; LOGAREZZI, Amede (Org.). Consumo e resíduo: fundamentos para o trabalho educativo. São Carlos: EdUFSCar, 2006, p. 19-41.

CAVALARI, Rosa Maria Feiteiro. A ideia de natureza no pensamento filosófico: a constituição de uma "Filosofia da Natureza" e sua contribuição para a Educação Ambiental, 2018, 132s. Tese (Livre-docência) - Instituto de Biociências, Universidade Estadual Paulista, Rio Claro, 2018.

CAVALARI, Rosa Maria Feiteiro; CAMPOS, Maria José Oliveira; CARVALHO, Luiz Marcelo de. Educação Ambiental e materiais impressos no Brasil: a relação homem-natureza. Educação: Teoria e Prática, Rio Claro, v. 9, n. 16, p. 1-18, 2001. CD-ROM.

DESCARTES, René. Discurso do Método. Tradução de J. Guinsburg e Bento Prado Júnior, 3. ed. São Paulo: Abril Cultural, 1983 (Os pensadores).

DUARTE, Rodrigo. Mímesis e Racionalidade: a concepção de domínio da natureza em Theodor W. Adorno. São Paulo: Loyola, 1993 (Coleção filosofia, 29).

DUARTE, Rodrigo. A arte. São Paulo: Editora WMF Martins Fontes, 2012 (Filosofias: o prazer do pensar).

FREITAG, Bárbara. A Teoria Crítica: Ontem e Hoje. São Paulo: Brasiliense, 2004.

GIACOIA JUNIOR, Oswaldo. Um direito próprio da natureza? Notas sobre tecnologia e ambientalismo: a técnica moderna e a ética. In: LIMA FILHO, Alceu Amoroso; POZZOLI, Lafayette (Org.). Ética no Novo Milênio: "busca do sentido da vida". São Paulo: LTr, 2004, p. 385-403 (Coleção Instituto Jacques Maritain).

GIL, Antonio Carlos. Como elaborar Projetos de Pesquisa, 5. ed. São Paulo: Atlas, 2010.

HORKHEIMER, Max; ADORNO, Theodor. Dialética do esclarecimento: fragmentos filosóficos. Rio de Janeiro: Jorge Zahar, 1985.

JONAS, Hans. O princípio responsabilidade: Ensaio de uma ética para a civilização tecnológica. Rio de Janeiro: Contraponto: Ed. PUC-Rio, 2006. 
MARCUSE, Herbert. A dimensão estética. Lisboa: Edições 70, 2016 (Arte \& Comunicação).

NAPOLITANO, Marcos. A relação entre arte e política: Uma introdução teórico-metodológica. Temáticas, Campinas, n. 19 (37/38), p. 25-56, jan./dez. 2011. Disponível em: < http:// www.unifesp.br/campus/gua/lapha/images/Material_apoio/arteepolticamarcosnapolitano. pdf> Acesso em: 23 jul. 2020.

RODRIGO, Lídia Maria. Considerações históricas sobre a dimensão ético-política da Educação. Quaestio: Revista de estudos de educação, Sorocaba, v. 3, n. 1, p. 45-54, abr. 2001. Disponível em: <http://periodicos.uniso.br/ojs/index.php/quaestio/article/ view/1424/1401>. Acesso em: 23 jul. 2020.

SALOMÉ, Josélia Schwanka. Educação, Arte e Formação Humana: Reflexões sobre a Educação Estética na Escola. In: JORNADA DO HISTEDBR - A Pedagogia Histórico-Crítica, a Educação Brasileira e os desafios de sua institucionalização,11, 2013, Cascavel. Anais... p. 1-11. Disponível em: http://www.histedbr.fe.unicamp.br/acer_histedbr/jornada/ jornada11/artigos/5/artigo_simposio_5_861_joselia.salome@utp.br.pdf . Acesso em: 23 jul. 2020.

SAVIANI, Dermeval. Onze teses sobre Educação e Política. In: SAVIANI, Dermeval. Escola e Democracia. São Paulo: Autores Associados, 1985, p. 91-101.

SEVERINO, Antônio Joaquim. A perspectiva dos valores na educação. In: SEVERINO, Antônio Joaquim. Educação, Sujeito e História. São Paulo: Olho d’Água, 2002, p. 83-97.

SILVA, Everson Melquiades Araújo; ARAÚJO, Clarissa Martins de. Tendências e concepções do ensino de arte na educação escolar brasileira: um estudo a partir da trajetória histórica e sócio-epistemológica da Arte/Educação. In: REUNIÃO DA ANPED, 30, 2007, Caxambu. Anais... p. 1-18. Disponível em: http://30reuniao.anped.org.br/grupo_estudos/ GE01-3073--Int.pdf. Acesso em: 23 jul. 2020.

STEVENSON, Robert, et al. The Evolving Characteristics of Environmental Education Research. In: STEVENSON, Robert (coord.). International Handbook of Research On Environmental Education. New York: Routledge, 2013, p. 512-517.

\section{DADOS DAS AUTORAS:}

\section{Heluane Aparecida Lemos de Souza}

Doutorado em Educação pela Universidade Estadual Paulista "Júlio de Mesquita Filho". Rio Claro/SP. Brasil. Professora de Educação Básica I na Rede Municipal de Ensino de Rio Claro/SP. Brasil. helu_souza@hotmail.com 


\section{Rosa Maria Feiteiro Cavalari}

Pós-doutorado em Educação Ambiental. Professora de Educação Ambiental da Universidade Estadual Paulista "Júlio de Mesquita Filho". Rio Claro/SP. Brasil r.cavalari@unesp.br

Submetido em: $30-4-2020$

Aceito em: $28-8-2020$ 